\title{
Comparison of Numerical Simulation and Experiment for the Microstructure Development of a Cold-rolled Multiphase Steel during Annealing
}

\author{
Norbert Kwiaton ${ }^{1, a^{*}}$, Roman Kuziak ${ }^{2, b}$, Maciej Pietrzyk ${ }^{3, c}$ \\ ${ }^{1}$ Salzgitter Mannesmann Forschung GmbH, Eisenhüttenstraße 99, 38259, Germany \\ ${ }^{2}$ Stanislaw Staszic Research Institute of Ferrous Metallurgy, ul. K. Miarki 12, 44-101 Gliwice, \\ Poland \\ ${ }^{3}$ AGH University of Science and Technology, al. Mickiewicza 30, 30-059 Kraków, Poland \\ an.kwiaton@sz.szmf.de, ${ }^{b}$ rkuziak@imz.pl, ${ }^{c}$ maciej.pietrzyk@agh.edu.pl
}

Keywords: AHSS, annealing, thermal cycles, numerical simulation, physical simulation

\begin{abstract}
JAMK model, developed as part of RFCS-project "VADPsheets", was applied to analyze different time temperature cycles from industrial time temperature cycle. The results of numerical simulation are compared with experimentally determined mechanical properties and microstructures. By distinguishing between recrystallized ferrite, ferrite after transformation, tempered martensite, bainite and martensite the experimentally obtained mechanical properties can be explained. The results of simulation can be used to optimize the properties and to generate a better understanding of process parameters.
\end{abstract}

\section{Introduction}

A noteworthy range of high and ultra high strength steels allows automakers to satisfy the need for low weight and improved passenger safety at acceptable costs. Special importance and a high market share have cold-rolled multiphase steels. Typical products in BIW are galvanized or annealed steel sheets at thicknesses between 0.7 to $2.5 \mathrm{~mm}$ [1]. Depending on the phase fractions and distribution, multiphase steels comprise dual phase (dp) and complex phase (cp) steels which are in the focus of this papers. Dual phase steels are known for their excellent combination of high tensile strength (TS) and good formability, involving a low yield strength (YS), high initial strain hardening rate, low yield ratio and relatively high total elongation (TE). At a strength level of about $800 \mathrm{MPa}$, dp steels shows typical values of YS of about $500 \mathrm{MPa}$ and $16 \%$ TE. For comparison, cp steels with the same TS have a YS of about $650 \mathrm{MPa}$ but a lower TE of about $12 \%$. Advantage of $\mathrm{cp}$ steels is the enhanced stretch flangeability, which is characterized by hole expansion ratio (HER) of more than $50 \%$, whereas dp steels show approximately $30 \%$ HER.

The microstructure and therefore the properties of these steels are primarily developed during the final continuous annealing/galvanizing process. The possibilities of the respective annealing or galvanizing lines and the resulting adjustable time temperature profile essentially determine the selection of chemical composition and of process parameters. Various metallurgical phenomena take place during annealing process. The most important processes occur during heating and soaking including the recrystallization of deformed ferrite, the dissolution of cementite followed by transformation to austenite involving redistribution of carbon between austenite and ferrite. During cooling, at first a reverse transformation of austenite to ferrite occurs. As a result of ferritic transformation, the content of carbon in the remaining austenite increases. During further cooling this austenite transforms into martensite and/or bainite. During overaging or heating to galvanizing temperature changes in martensite/bainite occurs and at the last step, the cooling to room temperature, the remaining austenite is transformed to martensite or a certain amount of austenite remains in the microstructure $[2,3]$. In the present study the developed model was applied to analyze the effect of different time temperature curves according to the industrial galvanizing process, on the final structure of investigated steel. 


\section{Experimental Material and Methodology}

Material. For the investigations, industrial cold rolled steel strip of $0.9 \mathrm{~mm}$ in thickness was chosen. The material was cold rolled from $2.6 \mathrm{~mm}$ hot strip with a cold rolling reduction of $65 \%$. The chemical composition of the steel is given in Table 1 . The microstructure after cold rolling consists of a typical mixture of deformed perlite and ferrite and shows a slight banding formation.

Table 1. Chemical composition

\begin{tabular}{|c|c|c|c|c|c|c|c|}
\hline $\mathrm{C}$ & $\mathrm{Si}$ & $\mathrm{Mn}$ & $\mathrm{P}$ & $\mathrm{N}$ & $\mathrm{Al}$ & $\mathrm{Cr}$ & $\mathrm{Nb}$ \\
\hline 0.16 & 0.39 & 1.53 & 0.009 & 0.006 & 0.04 & 0.23 & 0.013 \\
\hline
\end{tabular}

Dilatometer Experiments. Dilatometric experiments were conducted in order to generate material data for adjusting the developed phase transformations model parameters to experimental steel. The experiments were performed by means of a DIL 805 dilatometer using the samples machined from cold rolled material to dimensions of $0.7 \times 1.0 \times 7 \mathrm{~mm}^{3}$. The experiments focus on characterizing metallurgical changes occurring during the heating process and were therefore performed at heating rates of $3 \mathrm{~K} / \mathrm{s}$ and $60 \mathrm{~K} / \mathrm{s}$. To determine the fraction of recrystallized ferrite, the microstructure of subsequent samples was fast cooled after reaching different temperatures in the range between 400 and $850{ }^{\circ} \mathrm{C}$. To study the transformation during cooling, specimen were cooled down from a peak temperature of $850{ }^{\circ} \mathrm{C}$ at cooling rates between 0.5 and $409 \mathrm{~K} / \mathrm{s}$. The microstructure characterization was conducted with scanning electron microscopy.

Simulation of Annealing Process. Different temperature profiles similar to an industrial galvanizing process were tested to produce dual-phase and complex phase steels. Figure 1 shows a schematic illustration of the applied thermal cycles. The main difference between the two cycles is the temperature range of the slow cooling stage.

For the dp-cycle this temperature is much lower to transform more austenite to ferrite. Additional experiments with different annealing temperature and line speeds based on the dp-cycle were conducted.

Sheets of $450 \mathrm{~mm} \times 120 \mathrm{~mm}$ were annealed using the annealing simulator [4]. After annealing, tensile tests in longitudinal direction with standard A80 samples were conducted according to DIN EN ISO 6892-1. Light optical microscopy and in some cases scanning electron microscopy were applied to describe the microstructure of the specimens.

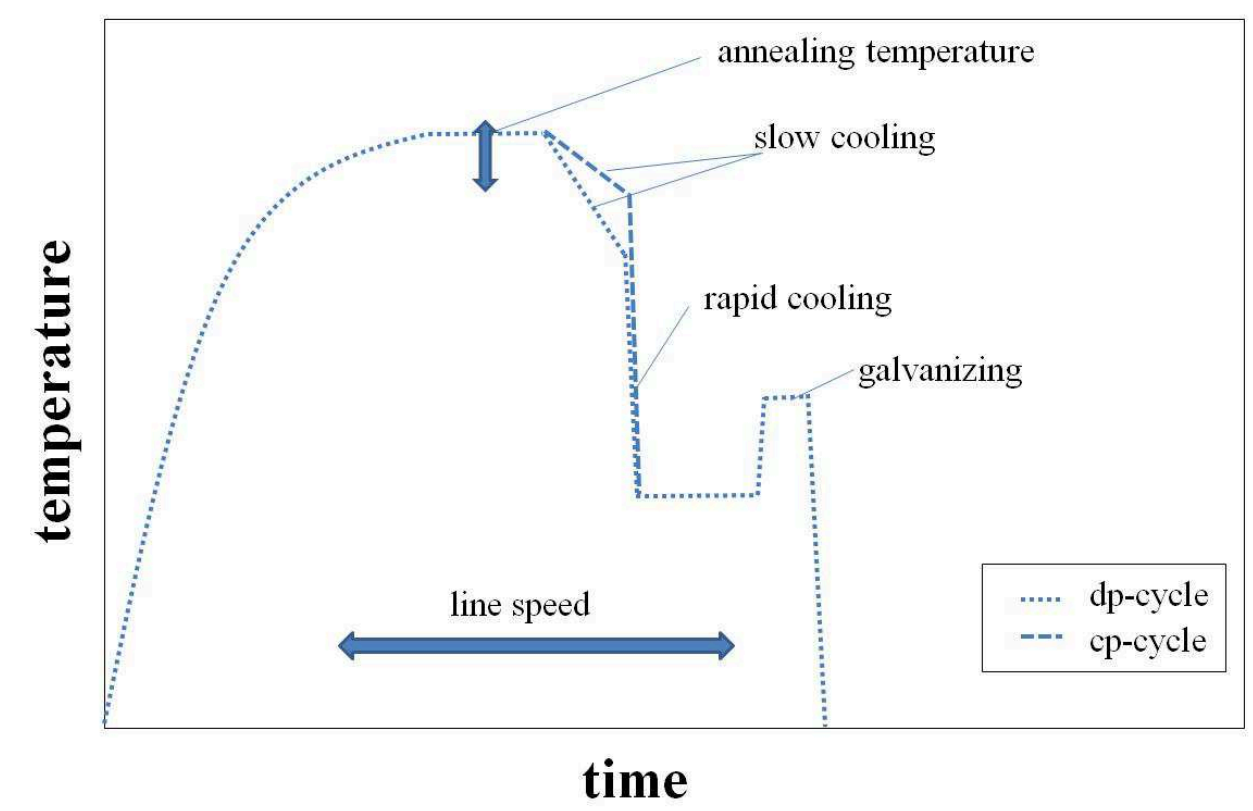

Fig. 1. Schematic illustration of used time temperature cycle 


\section{Results}

Phase Transformation Investigation and Model Development. Examples of the changes occurring in the microstructure during heating at a rate of $3 \mathrm{~K} / \mathrm{s}$ and for comparison at $60 \mathrm{~K} / \mathrm{s}$ are shown in Figure 2. The figure shows that heating rate affects both, ferrite recrystallization and transformation of ferrite/cementite into austenite. Comparison of these structures show that increasing the heating rate decreases the recrystallization volume fraction at $775{ }^{\circ} \mathrm{C}$ and this effect is quantitatively shown in Figure 3. The numbers in the graph were obtained using EBSD analysis and the details are presented in [5]. The heating rate also has substantial effect on the process of austenite formation. A low heating rate results in the spread of the cementite particles along the ferrite grain boundaries. This is confirmed by the presence of martensite in the sample heated to $775{ }^{\circ} \mathrm{C}$ followed by fast cooling. In the sample heated at rate of $60 \mathrm{~K} / \mathrm{s}$, mostly sub-grains are formed in the formerly deformed ferrite grains, and the cementite is not completely dissolved at $775^{\circ} \mathrm{C}$.

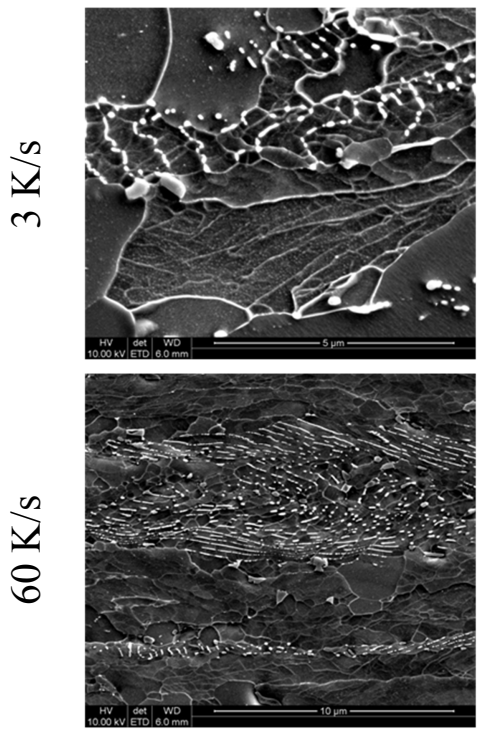

$750{ }^{\circ} \mathrm{C}$
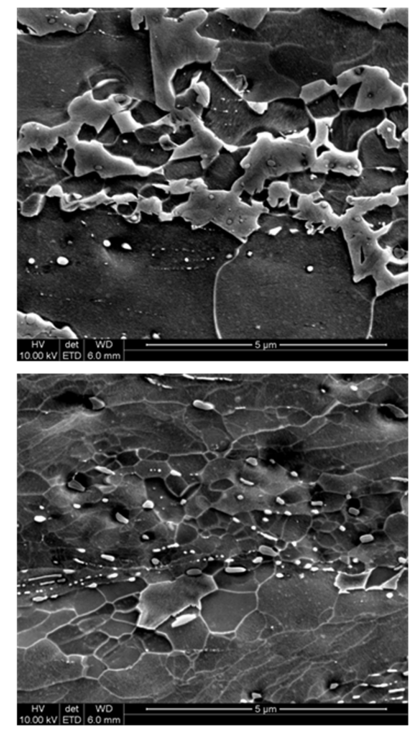

$775{ }^{\circ} \mathrm{C}$

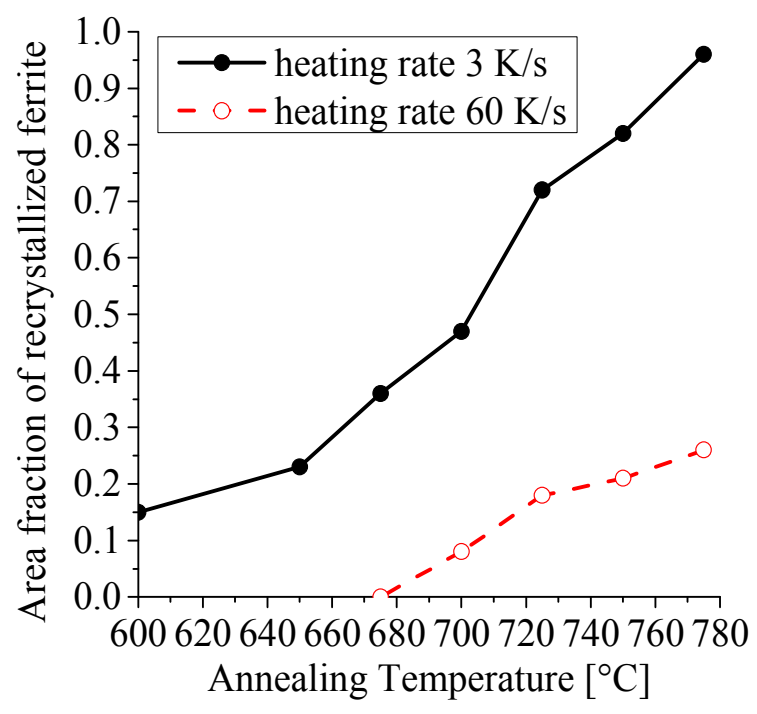

Fig. 2. Changes in the microstructure of cold rolled experimental sheet subjected to heating at a rate of $3 \mathrm{~K} / \mathrm{s}$ and $60 \mathrm{~K} / \mathrm{s}$ to different temperatures followed by fast cooling; FEG-SEM

Following the heating stage, the effect of cooling rate after reaching the peak temperature of $850{ }^{\circ} \mathrm{C}$ was studied in the dilatometer. Martensite appears in the structure for cooling rates greater than $1 \mathrm{~K} / \mathrm{s}$. Volume fraction of this constituent increases as cooling rate increases to approximately $207 \mathrm{~K} / \mathrm{s}$ and than decreases at the expense of bainite. This effect can be explained in terms of carbon content in austenite, since increasing the cooling rate from 207 to $409 \mathrm{~K} / \mathrm{s}$ reduces substantially the fraction of ferrite which subsequently causes a reduction of carbon content in the austenite. Even at the faster cooling rates ferrite is still formed in the microstructure.

The conventional phase transformation model based on the JMAK equation was developed:

$$
X=1-\exp \left(k t^{n}\right)
$$

where: $\mathrm{X}$ - transformed volume fraction, $\mathrm{t}$ - time

In this upgrade of the original JMAK model coefficient $\mathrm{k}$ was introduced as a function of temperature. The modified Gauss function was used to reproduce the rate of the transformation. Inverse analysis of the dilatometric test results was used to determine coefficients in the model. Details of the model are specific described in [6] and the material coefficients for the investigated steel are given in the report of RFCS project VADPSheets [5]. A Comparison of the model 
predicted transformation-start and -end temperatures with the results of dilatometric measurements shows its good predictive ability which is shown in Figure 4.

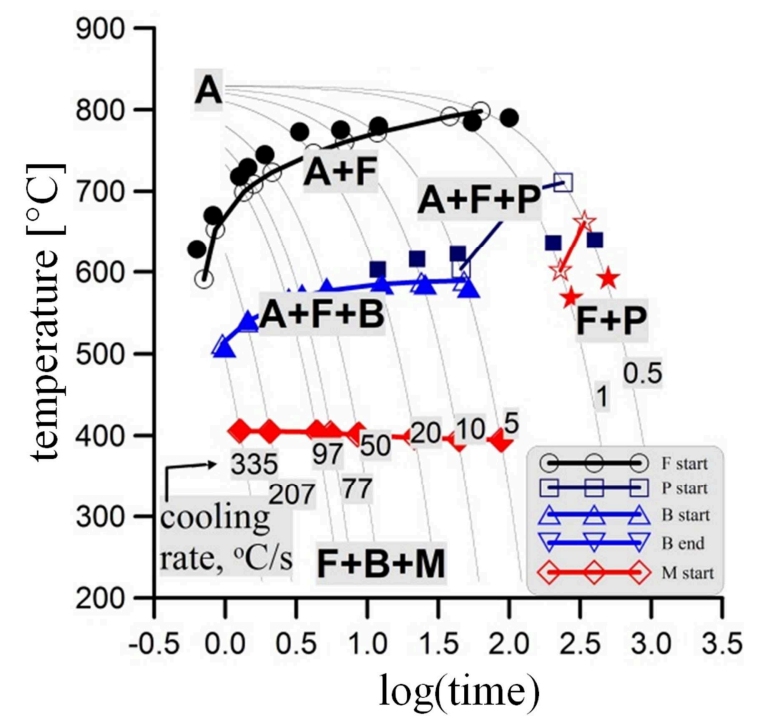

Fig. 4. Comparison of the predictions with the optimized model (open symbols) with measurements for the transformations start and end temperatures (closed symbols)

Results of the Annealing Experiments. As assumed by using the different thermal cycles for cp- and dp-cycles different metallographic structures were adjusted. The obtained microstructures are compared in Figure 5. When using the dp-cycle ferrite, martensite and a small amount of bainite are formed. In contrast, after annealing with cp-cycle the microstructure contains a markedly lower proportion of ferrite and martensite as well as larger amounts of bainite.

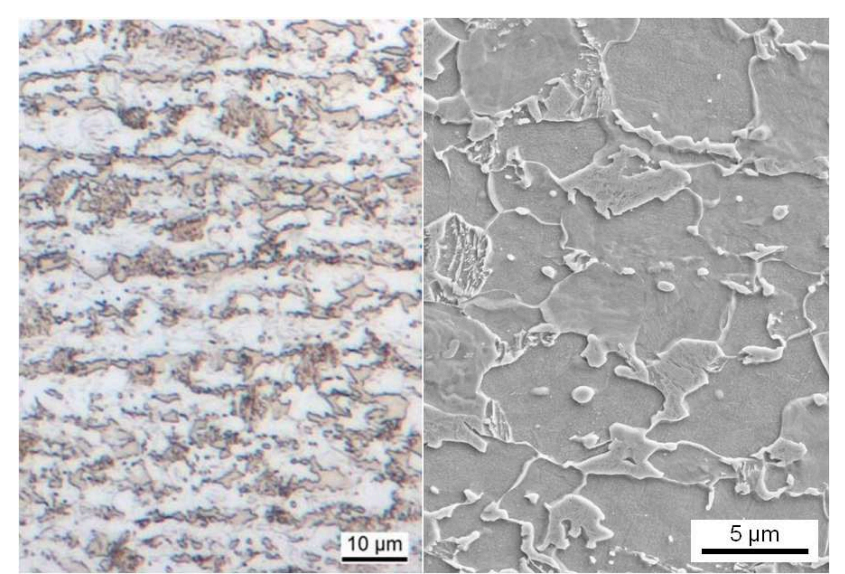

"dp-cycle"

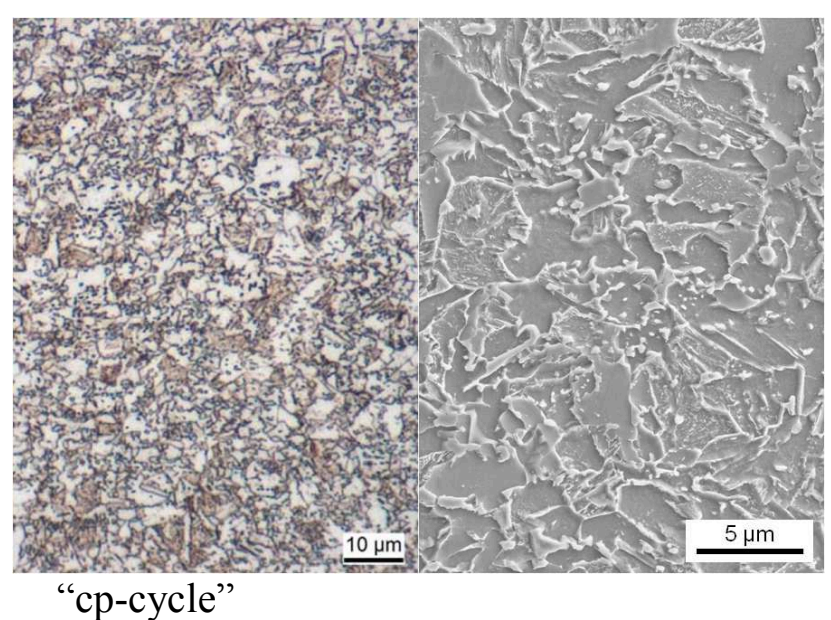

Fig. 5. LOM and SEM analysis of microstructures after annealing according to industrial annealing cycle for "dp-steel" and "cp-steel".

These different phase components affect the mechanical properties as shown in stress-strain diagram in Figure 6. Tensile and yield strengths are higher while the elongation values are lower after cp-cycle. Significant differences are reflected in the yield ratio, the yield ratio is 0.46 for $\mathrm{dp}$ cycle structure and 0.77 for cp-cycle material. 


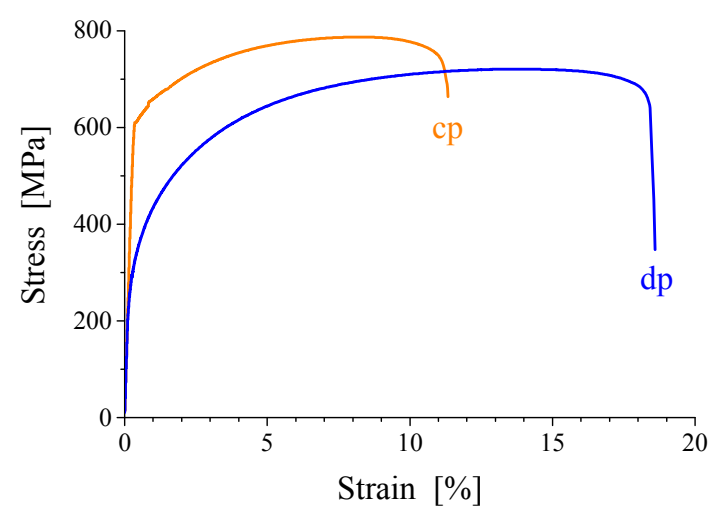

Fig. 6. Stress and strain curves from tensile for $\mathrm{dp}$ - and cp-steel

The maximum annealing temperatures were varied in this test in the range between $780{ }^{\circ} \mathrm{C}$ and $840{ }^{\circ} \mathrm{C}$ and tests at different line speeds at a maximum annealing temperature of $800{ }^{\circ} \mathrm{C}$ were carried out. Its influences on the mechanical properties are shown in Figure 7 and 8 . With higher line speed and higher annealing temperature slightly increasing tensile strengths and no significant effect on the yield strength are observed.

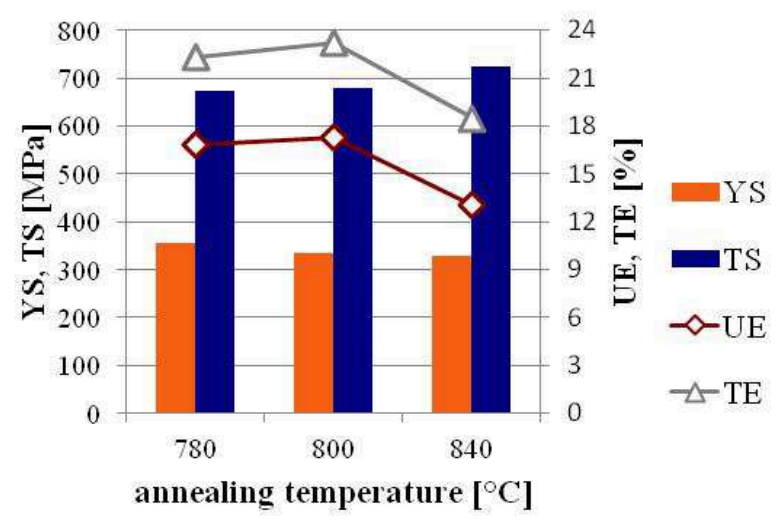

Fig. 7. Mechanical properties depend on annealing temperatures

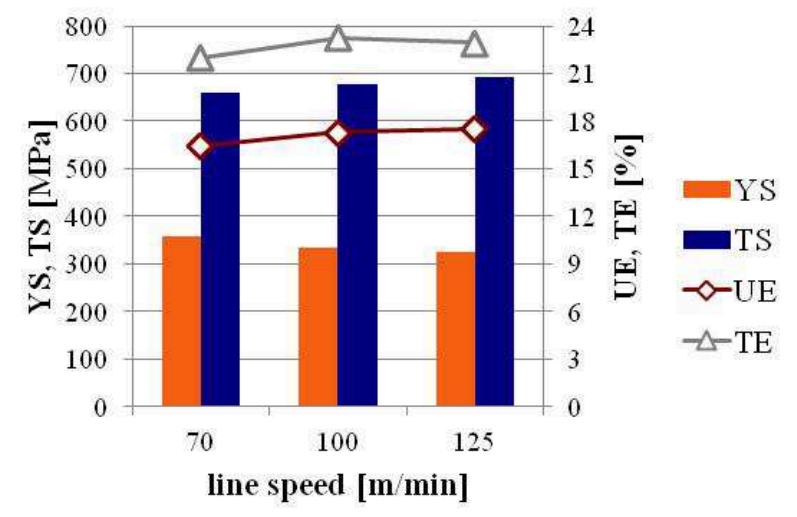

Fig. 8. Mechanical properties depend on line speed

In these cases the amount of martensite increases. The more interesting effect on the microstructure is shown comparing annealing at $780{ }^{\circ} \mathrm{C}$ (Figure 9) with annealing at $840{ }^{\circ} \mathrm{C}$ (Figure 10). The amount of martensite and bainite increases with higher annealing temperatures. The ferrite grain size is similar, but the appearance of ferrite grains is changed. At $780{ }^{\circ} \mathrm{C}$ annealing temperature the ferrite appear clearly delimited from each other and the martensite is mainly dispersed at the grain boundaries, whereas at $840^{\circ} \mathrm{C}$ annealing temperature boundaries between ferrite grains are no longer so keen to identify and martensite and bainite is embedded in these ferrite grains.

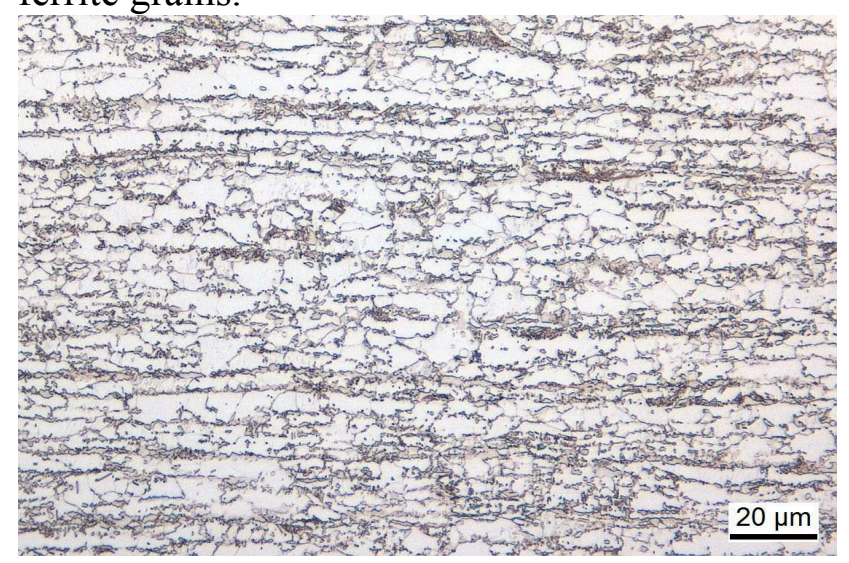

Fig. 9. LOM analysis of microstructures after annealing at $780^{\circ} \mathrm{C}$

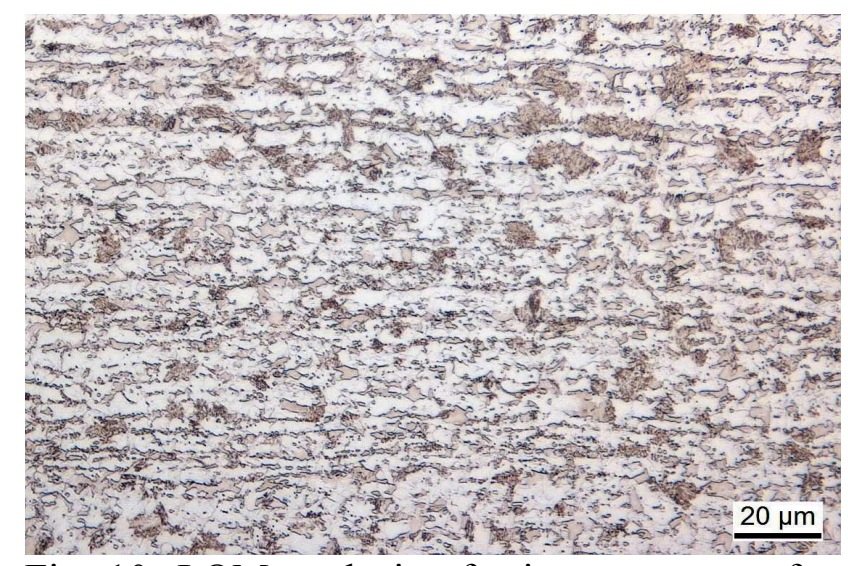

Fig. 10. LOM analysis of microstructures after annealing at $840{ }^{\circ} \mathrm{C}$ 
Results of the Simulation of Time Temperature Cycle. The different time-temperature cycles from experiments were simulated with the developed model. In Figure 11, the results of the numerical calculations of microstructure constituents can be seen for the dp- and cp-cycle. In both cases ferrite and pearlite is completely converted into austenite during heating. The transformation of austenite into ferrite occurs during the subsequent slow cooling from the peak temperature. In the further rapid cooling stage, different amounts of martensite are formed for both cycles. At the holding stage after rapid cooling, the formation to bainite starts. The volume fraction of bainite increases during the holding at zinc bath temperature, thereby the martensite, formed prior to the holding at zinc bath temperature, is also tempered. During the last stage of cooling to room temperature, new martensite is formed from the remaining austenite.
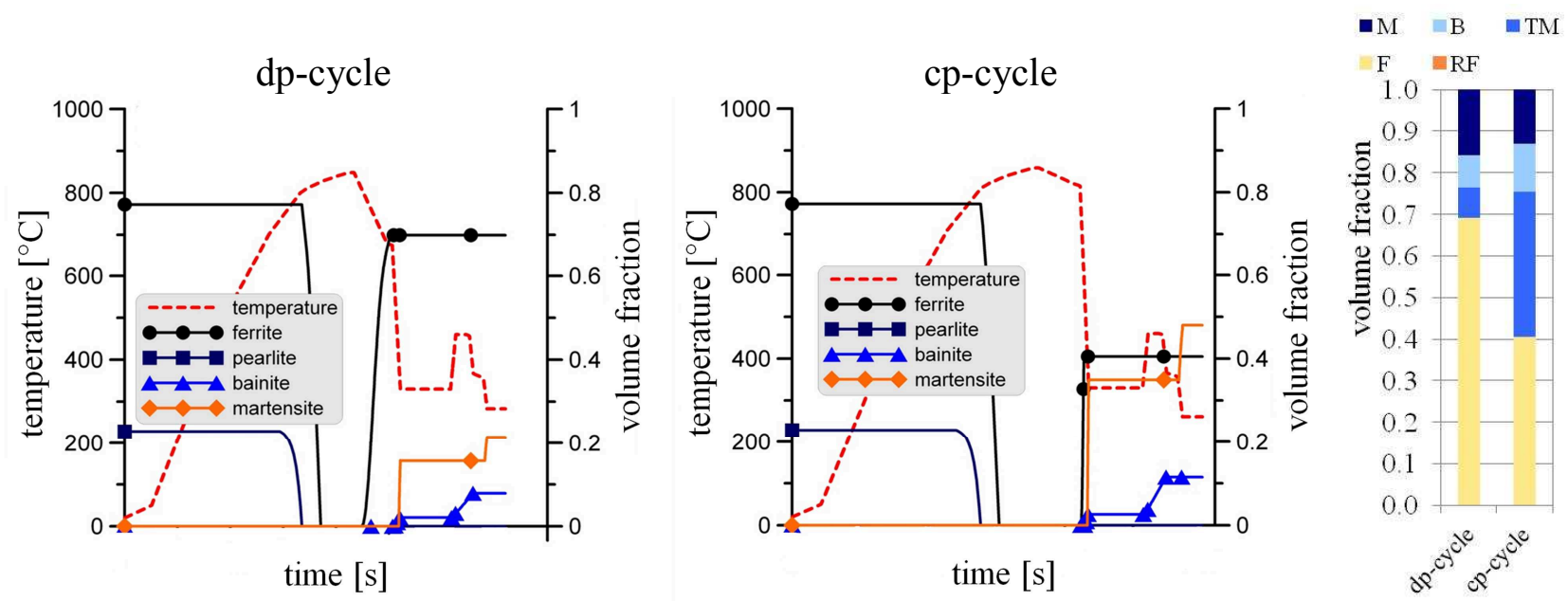

Fig 11. Results of the numerical calculation of the phase transformations occurring during dpcycle and cp-cycle with resulting microstructure constituents containing recrystallized ferrite $(\mathrm{RF})$, ferrite (F), tempered martensite (TM), bainite (B) and martensite (M)

The model was also used to determine the microstructure composition of the other dp annealing cycles. The results are shown in Figures 12 and 13. The calculations show that in all cases volume fraction of ferrite is very similar. However, the fraction of recrystallized ferrite (old ferrite) and ferrite obtained as a result of austenite decomposition during cooling are different. Furthermore, the low temperature constituents have different fractions of martensite, tempered martensite and bainite. At annealing temperature of $840{ }^{\circ} \mathrm{C}$ (Figure 12) a higher fraction of martensite is formed, than compared to annealing $780{ }^{\circ} \mathrm{C}$ and $800{ }^{\circ} \mathrm{C}$. A higher line speed (Figure 13) increases the fraction of recrystallized ferrite, the total amount of ferrite slightly decreases and the proportion of martensite increases.

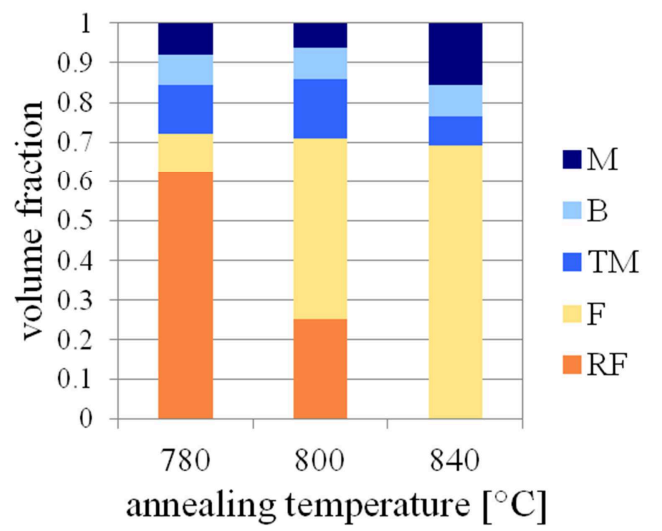

Fig. 12. Results of numerical calculations of the dependence of microstructure constituents on annealing temperature

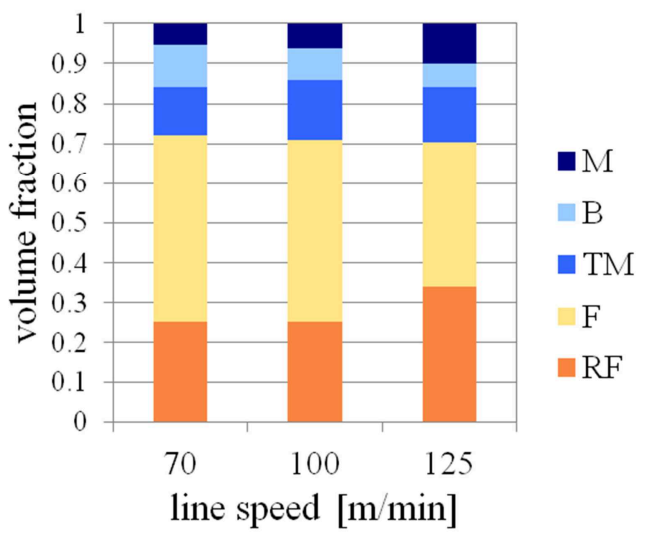

Fig. 13. Results of numerical calculations of the dependence of microstructure constituents on line speed 


\section{Summery}

The numerical simulations with the developed JMAK model are in reasonable agreement with the experimental results. For two different annealing cycles for dp- and cp-steels the microstructure constituents are calculated accurately. A prediction of ferrite fractions succeeds sufficiently. However, the amount of martensite is somewhat underestimated for the dp-cycle while the amount of martensite for the cp-cycle seems slightly too high. This is probably due to the fact that the effect of increasing carbon content in remaining austenite on the martensite-start temperature was not captured in the course of dilatometric investigation, and thus, was not accounted for in the developed model. The incorporation of this effect will be subject of further studies.

Examining the various dp-cycles with different annealing temperatures and a variation of the line speed, the mechanical properties showed only slight differences. In the simulation it was found that the proportion of total ferrite is nearly constant. However, differences exist in the fractions of recrystallized ferrite (RK) and in the composition of the hard phase fractions of martensite, bainite and tempered martensite.

The differences between the two types of ferrite may be explained by a different appearance of the microstructure as shown in Figures 9 and 10. The different proportions of martensite cause the increase of tensile strength. However, the other structural components must also be considered.

\section{References}

[1] AHSS Guidelines Version 5.0, May 2014 on http:// www.worldautosteel.org .

[2] G. R. Speich, R.L. Miller. In: R.A. Kot, J.W. Morris, editors. Structure and properties of DualPhase steels, New York (NY): The Metallurgical Society of AIME, (1979) 145.

[3] M. Militzer, Microstructure evolution in dual-phase steels, Trans. Indian Inst. Metals, 59 (2006) 711-724.

[4] M. Niemeyer, T. Schulz, U. Eggers, T. Evertz, F. Luther, The New Salzgitter Mannesmann Forschung Technology Center Continuous R\&D Process Chain - Systematic Product Development, steel research international, 79 (2008) 396-400.

[5] Property oriented design of hard constituent hardness and morphology in continuously annealed/galvanized DP sheets - VADPSheets - Contract Number: RFSR-CT-2011-00014.

[6] J. Lin, D. Balint, M. Pietrzyk, Microstructure evolution in metal forming process, eds., Woodhead Publishing in Materials, (2012) 145-179. 